\title{
Iron Urine Excretion Rate
}

National Cancer Institute

\section{Source}

National Cancer Institute. Iron Urine Excretion Rate. NCI Thesaurus. Code C117838.

A determination of the amount of iron being excreted in urine over a defined period of time. 